\title{
DETERMINATION AND OPTIMIZATION OF COMPRESSION ZONE LENGTH FOR POLYPROPYLENE FIBER PROCESS
}

\author{
Yousif A.A, Seedahmed A.I, Muhab.Hassanien S.S \\ Sudan University of Science and Technology \\ Department of Polymer Engineering, Sudan
}

\begin{abstract}
Extrusion process is one of the most flexible and important operation for mass production of plastic product. In extrusion process, screw design is very important as it is largely affects the productivity and quality. The technical knowhow in these mills is based on experience of the employee thus processes are designed by trial and error without applying professional engineering design of the process. In this study focus was applied on analyzing and modeling the compression zone, which is considered to be the most important and complicated zone in the screw. An equation was derived so to determine the length of the compression zone that is suitable to produce polypropylene fibers
\end{abstract}

Keywords - Extrusion process, compression zone, modeling, screw design, polypropylene fiber.

\section{INTRODUCTION}

Many theoretical, experimental, modeling and simulation studies have already described the polymer behavior in Extrusion process focusing on the polymer flow inside the barrel [1-3]

Extrusion process is the most important and most massive technology in the polymer processing industry. It is widely used for the production of fibers, films, sheets, pipes, and profiles. Extrusion also used for special processing operations, such as compounding, mixing, granulating, chemical reactions, and more. These operations are applied for most polymeric materials. [4]

The design of polymer processing is currently supported by computer simulations based on the mathematical models of manufacturing processes. Modeling makes it possible to predict the course of these processes on the basis of process data (material, operation, and geometry).[5] The extruder screw is one of the most important component of the machine, it's design is crucial in the mixing and process ability of the polymer in question, with respect to the type of polymer to be process. The screw is designed into five different sections known as zones. Different types of polymer may have different screw design; some design may not have the entire zones.[6] . Three zones are usually identified in most screw which are shown in Figure1.

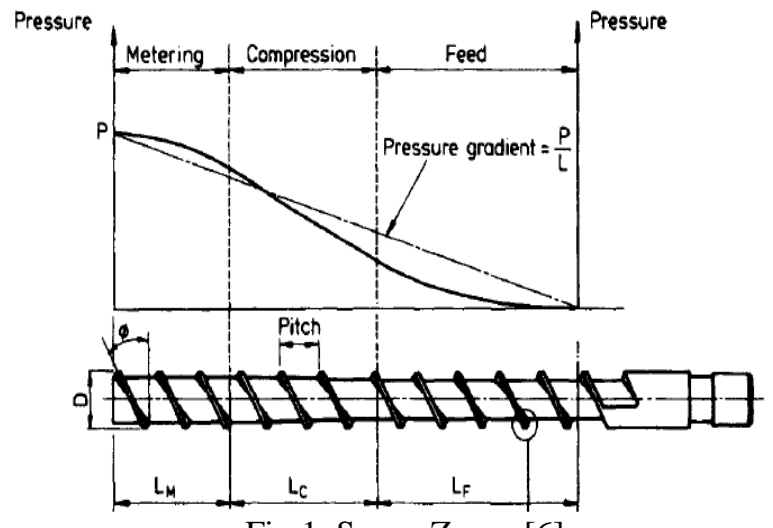

Fig.1. Screw Zones [6]

Many research about screw zones and geometry has been conducted. Experimental analysis for extrusion screw geometry to produce highly transparent polypropylene sheets was investigated. The observation was experimentally conducted by using many screws with various geometries to obtain a highly transparent polypropylene melt resin sheet. The pressure distribution in the extruder, melt temperature profile across melt flow, the extruder throughput and the specific energy consumption were monitored.[7] The work obtained screw geometry optimization was conducted using the analysis of melting performance by the cooling experiment and the pressure pattern. As a result, the screw geometry to satisfy a low external haze and an extrusion stability under higher throughput conditions was designed.

A. Farhoumand (2016) were applied a finite element method to investigate the effect of process parameters of plastic deformation behavior in Forward-Backward-Radial Extrusion (FBRE) process. The result of an ax symmetric model shows that the friction between die components and the sample has a substantial effect on the material flow behavior.[8]

W.E. Abdel-Ghany (2015) investigated the characteristics of single screw extruders and evaluate the performance of various types of screw under different working conditions using finite element analysis. [3]

Tingrui (2017) used a statistical, design of experiments (DoE) approach. For a conventional screw design, barrel 
temperature, screw speed and two vastly different melt viscosity PP mixtures were selected as the independent factors, whilst melt pressure, mass output, screw torque and temperature rise at the die due to shear heating, were the dependent responses.[9]

ZHOUKE (2014) used POLYFLOW simulation plat form to model and analyzed the single screw extrusion process of propellant through the application of Finite Element Analysis on extrusion of plastic. The distributions and changes of viscosity in extrusion process. [10]

A. Lewandowski (2019) applied ANSYS Polyflow software to model the melt flow in the extruder and analyzed the flow of polymers with slip effects both in the screw (on the screw and barrel surfaces) and in the die. Screw pumping characteristics and die characteristics are calculated and modeled for various power law indices, and various slipping parameters. The effect of slipping on extruder operation is discussed.[11]

In this paper, we have used analytical calculations for modeling the polypropylene melt flow to determination the length of the compression zone this zone is one of the most importent zone for single screw extruder.

\section{ANALYSIS AND DESIGN}

The polypropylene data as shown in table (1) are used to analyze and design the single screw extruder to determine the compression zone length suitable for polypropylene extrusion process.

Table 1: Specifications of Polypropylene

\begin{tabular}{|c|c|c|}
\hline Trade Name & The Units & The Value \\
\hline Density & $\mathbf{k g} / \mathbf{m 3}$ & $\mathbf{9 1 0}$ \\
\hline Melting point & ${ }^{\circ} \mathbf{C}$ & $\mathbf{2 1 0}$ \\
\hline Heat diffusion & $\mathbf{J} / \mathbf{k g}$ & $\mathbf{2 3 . 4}$ \\
\hline $\begin{array}{c}\text { Medium } \\
\text { temperature }\end{array}$ & ${ }^{\circ} \mathbf{C}$ & $\mathbf{3 0}$ \\
\hline $\begin{array}{c}\text { Eject temperature } \\
\text { Thermal } \\
\text { conductivity }\end{array}$ & ${ }^{\circ} \mathbf{C}$ & $\mathbf{6 0}$ \\
\hline $\begin{array}{c}\text { Melting occurs at } \\
\text { the adjacent film }\end{array}$ & $\mathbf{J m m}-\mathbf{0 . 1 7 2}$ \\
\hline Mass Flow Rat & $\mathbf{~ K g / h}$ & $\mathbf{1}$ \\
\hline
\end{tabular}

\section{A. Screw Analysis and design :}

In this paper the analysis of single screw extruder is concentrated on the analysis of metering zone for determination and optimization of length of this zone, which is suitable to produce polypropylene fiber used in ropes manufacturing. An equation was derived using several equations, as explained below :

$$
L=\frac{A}{\pi D}[6](1)
$$

Where $\mathrm{L}$ is the length of compression zone, $\mathrm{A}$ is the heating area, D screw diameter.[6] [6]

The total flow was calculated in extruder using equation (2) which may be written as:

$\mathrm{Q}=\frac{1}{2} \pi^{2} D^{2} N H \sin \varphi \cos \varphi-\frac{\pi D H^{3}}{12 \mu} \sin ^{2} \varphi \frac{d p}{d l}[6]$

Where $\mathrm{Q}$ is total flow , $\varphi$ is screw flight angle, $\mathrm{N}$ is the screw speed, dp is the change in pressure, $\mathrm{L}$ is the change in length ,D is the screw diameter, $\mu$ is melt viscosity, $\mathrm{H}$ is the screw channel depth. are used equation as shown below to determine heating area:

$\mathrm{A}=\frac{Q_{h}}{h \theta_{m}}$

Where $A$ heating area, $Q_{h}$ is heating requirement from the heaters, $\mathrm{h}$ is the heat coefficient of polypropylene , $\theta_{\mathrm{m}}$ is the change temperature at the melting zone. The heating (melting zone) is considered as a shell at a constant temperature $\mathrm{T}$ and the melt leaves this area at $\mathrm{T}_{\mathrm{t}}$ The material enter at $\operatorname{Tr}$ (room temp) to calculate the change temperature in melting used equation as shown below:

$$
\theta_{m}=\frac{\left(T-T_{r}\right)-\left(T-T_{t}\right)}{\ln \left(\frac{\left(T-T_{r}\right)}{\left(T-T_{t}\right)}\right.}
$$

Where constant temperature of PP material, $T_{t}$ is temperature of melt at leaves of the metering zone, $\mathrm{T}_{\mathrm{r}}$ is the temperature of the material entire metering zone (room temperature). The heat coefficient of PP was calculated using the equation written as:

$$
h=\frac{k}{\delta} \quad[6]
$$

Where $\mathrm{k}$ is thermal conductivity of PP material, $\delta$ is Melting occurs at the adjacent film. The heat requirement from the heaters is calculated by using the equation shown below:

$\dot{Q}_{\mathrm{h}}=\mathrm{A} \mathrm{h} \theta_{\mathrm{m}} \quad$ [12]

The total heat requirement to melt PP material was calculated using the equation as may be written below:

$$
\dot{Q}_{t}=\dot{m} \Delta \mathrm{H}_{F} \quad[6]
$$

Where $\mathrm{Q}_{\mathrm{t}}$ is the total heat requirement to melt PP material, $\dot{m}$ is mass flow rate, $\Delta \mathrm{H}_{F}$ is the heat of fusion of PP

B. From all the above mentioned equations a model equation was derived to determine the suitable compression zone length for manufacturing the polypropylene fibers. the equation is as shown below:

$$
\mathrm{L}_{C}=\frac{0.9 \dot{m} \Delta h_{f} \delta \operatorname{Ln}\left[\frac{T-T_{r}}{T-T_{t}}\right]}{\pi D K\left[T_{t}-T_{m}\right]}
$$




\section{International Journal of Engineering Applied Sciences and Technology, 2021 \\ Vol. 5, Issue 9, ISSN No. 2455-2143, Pages 27-29 \\ Published Online January 2021 in IJEAST (http://www.ijeast.com)}

\section{RESULT AND DISCUTION}

The single screw was analyzed, specifically the compression zone, which is the most important zone in the screw, and the aim was to determine its appropriate length for the process of manufacturing polypropylene fibers used in the manufacture of ropes. An equation was resulted which is to be used for the determination of the length. To reach this equation, some considerations inherent in the melting and flow of the molten process were taken in account, such as the amount of heat required from the heaters and the resultant of the shear, the area to be heated, the heat transfer coefficient and the use of the data on the physical, thermal, and rheological properties of polypropylene .The length of the compression zone was calculated using this equation and compared with the real value of the length of the compression zone of the ropes making manufacturing that was manufactured by trial, error and experience, and the same result was obtained.

\section{CONCLUSION}

In this study, an equation was derived that helps designing extrusion machines. It will solve many problems for machine designers so as to reduce the cost, time and effort gained in designing through trial and error experience.

\section{REFERENCE}

[1]. Sastrohartono T, Jaluria Y, Esseghir M and Sernas V .(1995).A numerical and experimental study of threedimensional transport in the channel of an extruder for polymeric materials. International journal of heat and mass transfer 38:1957-1973.

[2]. Han CD, Lee KY and Wheeler NC.(1990).An experimental study on plasticating single-screw extrusion. Polymer Engineering \& Science 30:1557-1567.

[3]. Abdel-Ghany W, Ebeid S and Fikry I .(2015).Mechanical Design Aspects of Single Screw Extruders using Finite Element Analysis. International Journal of Engineering and Technical Research (IJETR) 3:245 - 4698.

[4]. Nastaj A and Lewandowski A. (2019).Wilczy nski, KJ; Buziak, K. Fundamentals of global modeling for polymer extrusion. Polymers 11:2106.

[5]. Baird DG and Collias DI .(2014). Polymer processing: principles and design. John Wiley \& Sons.

[6]. Crawford RJ (1998) CHAPTER 5 - Analysis of polymer melt flow. In: Crawford RJ (ed)^(eds) Plastics Engineering (Third Edition), Butterworth-Heinemann, Oxford pp. 343-412 [7]. Funaki A, Takubo T and Kanai T .(2010). Experimental analysis for extrusion screw geometry to produce highly transparent polypropylene sheets. Polymer Engineering \& Science 50:420-427.

[8]. Farhoumand A and Ebrahimi R. (2016).Experimental investigation and numerical simulation of plastic flow behavior during forward-backward-radial extrusion process. Progress in Natural Science: Materials International 26:650656.

[9]. Fu T, Haworth B and Mascia L. (2017). Analysis of process parameters related to the single-screw extrusion of recycled polypropylene blends by using design of experiments. Journal of Plastic Film \& Sheeting 33:168-190. [10]. Ke Z, Zhongqi H, Shupan Y and Wanghua C. (2014). Numerical simulation for exploring the effect of viscosity on single-screw extrusion process of propellant. Procedia Engineering 84:933-939.

[11]. Lewandowski A and Wilczyński K .(2019).Global Modeling of Single Screw Extrusion with Slip Effects. International Polymer Processing 34:81-90.

[12]. Tadmor $\mathrm{Z}$ and Gogos CG. (2013).Principles of polymer processing. John Wiley \& Sons. 